\title{
The steppe marmot-its past and future
}

\author{
Dmitri I. Bibikov
}

The steppe marmot of European Russia has suffered from hunting pressure and agricultural development in the past. Now it is regaining its former range by colonizing abandoned farming areas and this process is being helped by reintroduction programmes. Once secure these marmots show considerable potential for increase and could form the basis for a useful and substantial harvest in the future.

\section{Introduction}

Opinions differ on how many marmot species there are in Eurasia, with different authors recognizing between one and eight species and a number of subspecies (Zimina and Gerasimov, 1973). The taxonomic problems of the genus Marmota are still to be resolved, although the new systematic methods now being used should help.

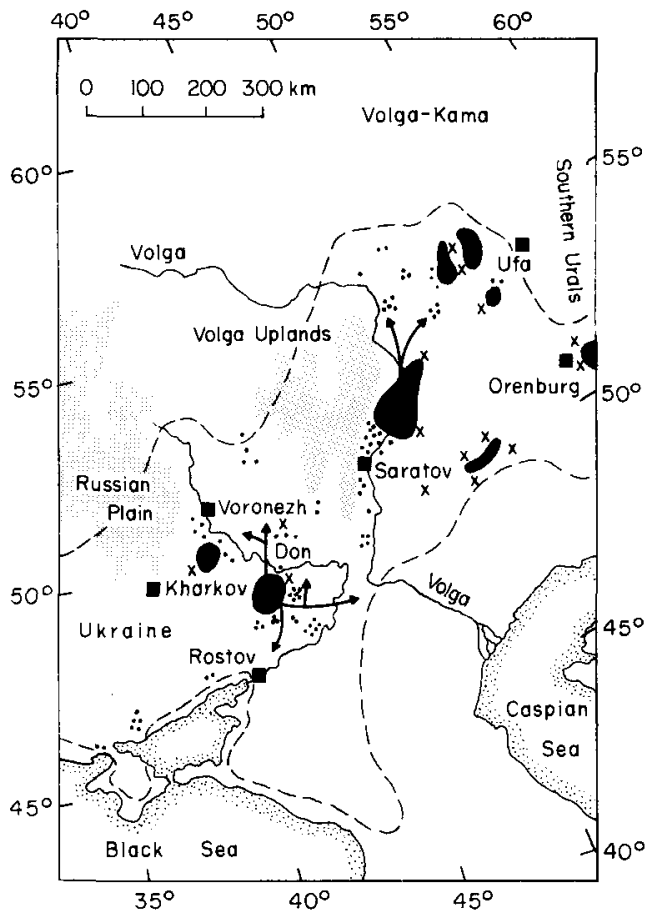

Figure 1. Past and present distribution of Marmota b. bobac.
Of the Eurasian marmots, only one, the steppe marmot Marmota bobac, inhabits the steppes, the rest being mountain dwellers. The species has suffered severe pressure from man's activities: large parts of its range have been ploughed and it has been intensively hunted. Despite this, the prospects for its survival are good, due to its vast potential range and its ability to adapt to agricultural landscapes.

In Russia there are two recognized subspecies : $M . b$. bobac in eastern Europe and $M$. $b$. schaganensis east of the Urals in Kazakhstan (Figure 1). The total number of $M . b$. bobac now number 250,000 (Bibikov and Dezhkin, 1988). The Kazakhstan subspecies, which is distributed eastwards from the southern Urals and which had declining numbers for some decades, has now stabilized at nearly 1,000,000 individuals.

This paper outlines the history of the steppe marmot of European Russia and discusses its past declines and recent recovery.

\section{Historic range}

During the Pleistocene the range of $M$. bobac in eastern Europe contracted and expanded considerably with the climatic fluctuations. Its deep-burrowing habits and ability to hibernate through long severe winters made it well adapted for survival in the open landscapes of the periglacial zone and it was able to migrate over long distances. As the glaciers retreated for the last time and the coniferous and deciduous forests spread northward, the marmot 
was forced back to the forest-steppe and steppe areas of eastern Europe (Zimina and Gerasimov, 1971, 1973).

Over the last few centuries the distribution of $M . b$. bobac in eastern Europe has been determined by human activities. Until the eighteenth century it was abundant and ranged widely in the steppes of the Russian plain and in the piedmont of the southern Urals. By the beginning of this century it was nearly exterminated by ploughing and excessive hunting in the greater portion of its range. By the 1930s-1950s depleted colonies remained only in two parts of the Ukraine, in the southern Voronezh and north-eastern Rostov regions, in the Volga Uplands and the steppe piedmont of the southern Urals (Figure 1).

\section{Reasons for the decline}

M. bobac, like other marmots, is ecologically associated with wild ungulates, whose grazing maintains a high diversity of plants in the steppe or mountain pastures. Virgin steppes without wild ungulates or their modern replacement, livestock, are not suitable for marmots. The lack of grazing results in an impoverishment of forage species composition and the thick mat formed by dead rhizomatous plants hampers new growth, resulting in a scarcity of food in spring. At present pastures for livestock are the most typical habitat for the marmot.

In historic times the major causes of the reduced range and numbers of $M . b$. bobac were agricultural development and hunting. In the mid-nineteenth century the proportion of ploughed lands grew rapidly in the Ukraine and in the Don and Volga areas. The marmot was forced into unsuitable lands, small, flatbottomed valleys, ravines, forest borders and other areas that had not been ploughed. It survived mainly in areas with dissected relief, where stud farms were often situated and pastures were not ploughed. Hunting for the fur and fat also affected the species very seriously, often causing local exterminations. In the Volga-Kama area the marmot populations were heavily depressed, especially in 1921-22 when

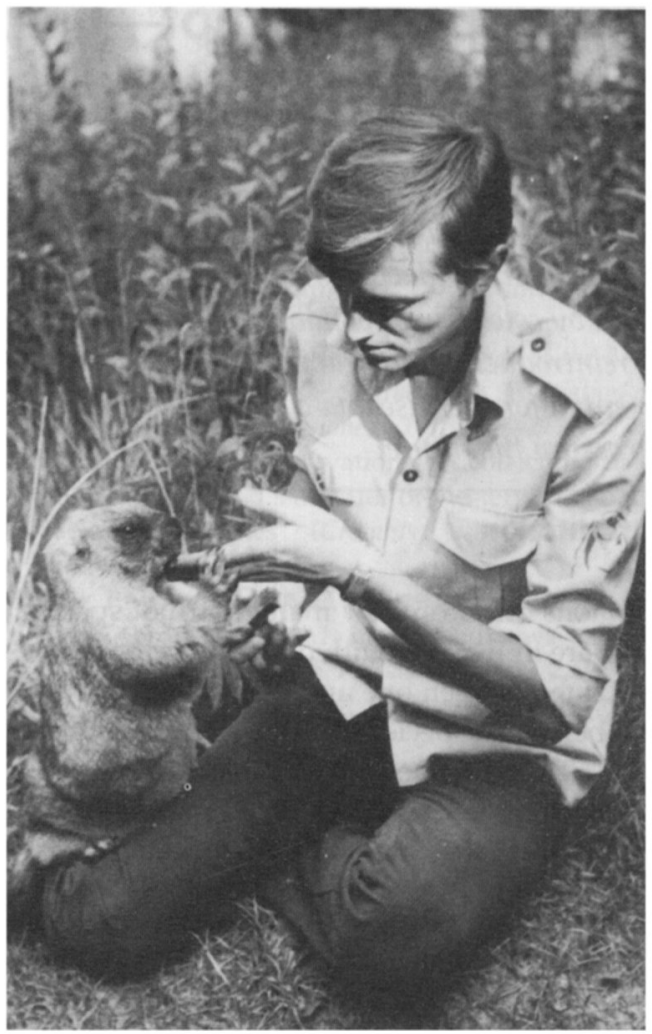

The steppe marmot (V. A. Jokazsky)

food shortages caused local people to use its meat. The same happened in the Ukraine and the Volga area in the early 1930s and in times of hardship in the past marmots have saved people from starvation. In several areas of Tataria marmots were hunted for food during the Great Patriotic War (1941-1945) (Popov, 1960).

Thus, the fragmented range of M. b. bobac in the first half of this century was a result of human activity. Populations were isolated, some colonies numbering only a few animals (Figure 1). Only several thousand animals survived in a vast area from the Ukraine to the piedmont of the southern Urals.

\section{Restoration of $M$. bobac bobac}

As a result of hunting prohibition and conservation measures and also due to some other factors, which have not been identifed completely, population numbers began increasing 
in the 1950s, first in the Ukraine, then in the Volga area and westward from the Urals. Tokarsky (1988) studied this population growth and range expansion in the Kharkov region (Figure 2). Although numbers increased and range expanded between 1940 and 1980, from 1981 to 1987 the Kharkov population decreased by nearly 17 per cent. This was due to illegal hunting and also because of lowered reproduction in overpopulated colonies. A similar phenomenon was observed in the Don and Volga regions.

Villages and farmsteads abandoned in the move to cities have a striking role in the restoration of the marmot's range. From a helicopter you can see very clearly how marmots have colonized abandoned human settlements. For example, in the south of the Voronezh region marmot families occupy every weedcovered hillock that remains from human disturbance. Among foundation and stove ruins you can see mounds of earth from numerous burrows. When a portion of a village is still occupied marmots settle in the part that has been abandoned. When crossing such a deserted village curious and trusting animals can be seen everywhere.

This new habitat meets the major needs of the animal: settlement ruins are usually situated in open uplands with a wide horizon; there is a wide diversity of plants in active growth from early spring until late autumn; and there are many suitable burrow sites. Having settled near man, the marmot becomes very trusting, and when not hunted, it does not fear noisy vehicles. If an encounter with people promises danger (unfortunately, poaching with vehicles is still frequent), marmots hide in their burrows as soon as they hear the sound of an engine.

The rate of dispersal has been ascertained for some areas of the Voronezh and Orenburg regions. It averaged 7-8 km per year, but there were periodic pauses to allow time to settle and breed in a new area.

Until the 1970s the range of the steppe

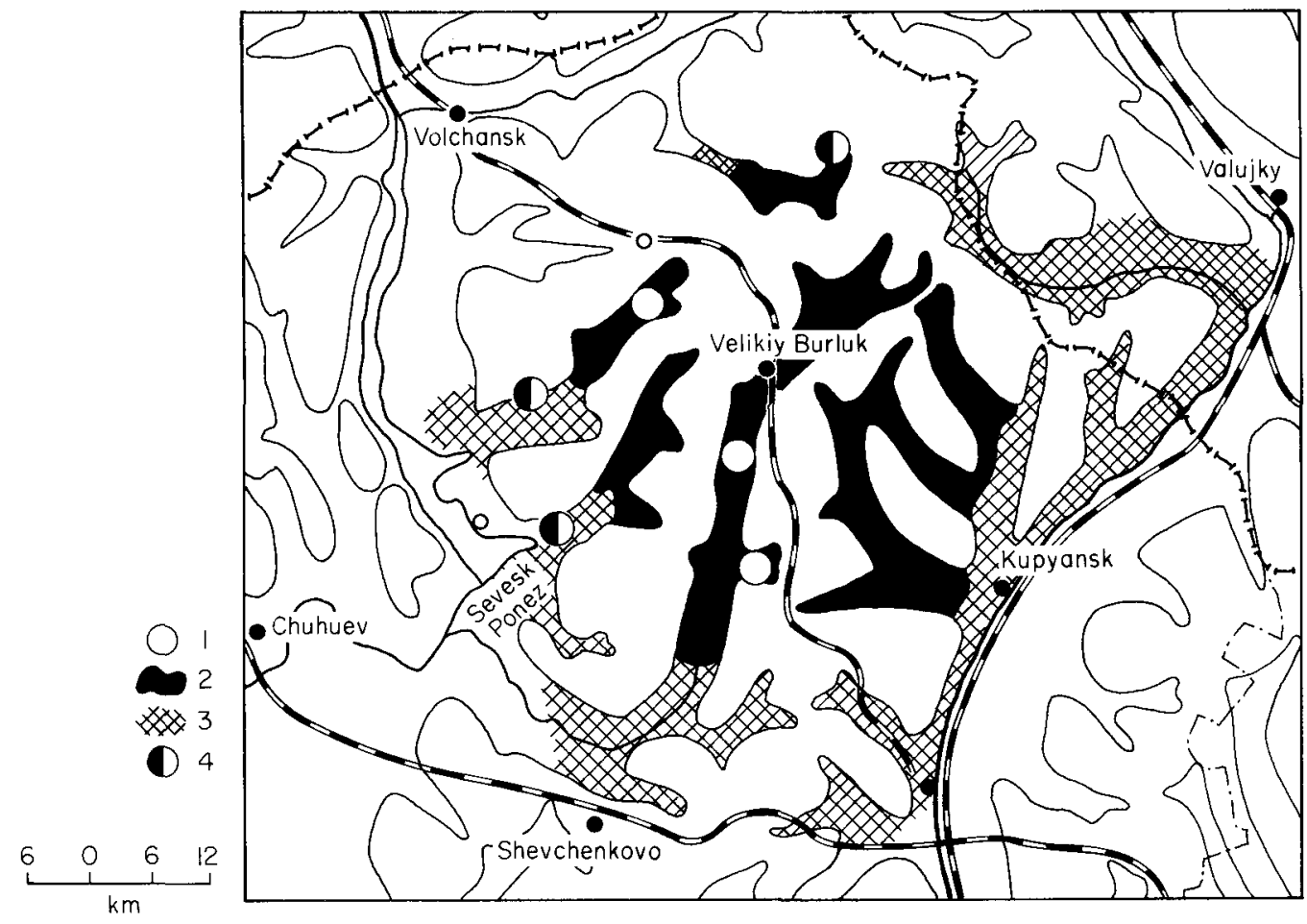

Figure 2 (a). Changes in the range of the Kharkhov population of M. b. bobac 1920s-1980s. 1. 1920-1940; 2. 1941-1960; 3. 1961-1980; 4. Sites whose colonies vanished in the 1980s. 


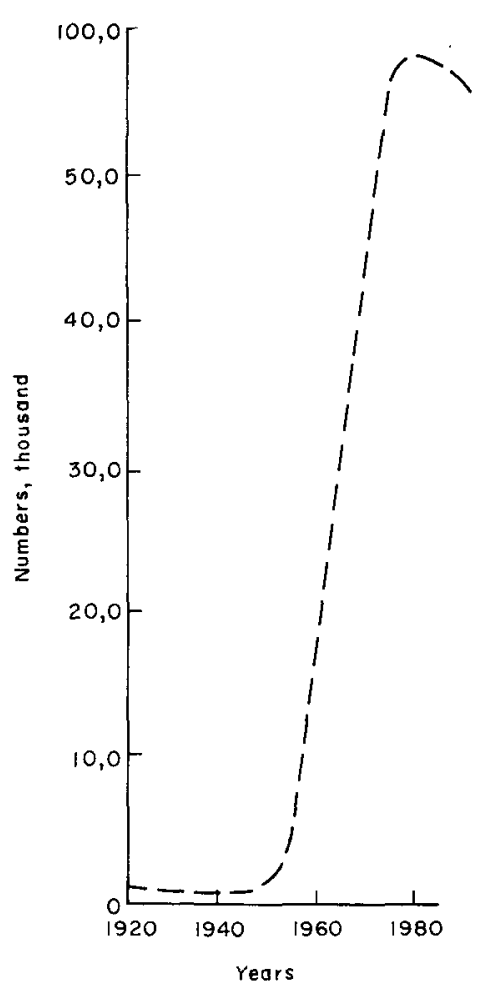

Figure 2 (b). The change in numbers of marmots in the period 1920-1980.

marmot was expanding naturally in those areas where its colonies had survived during the depression, for example in the Kharkov region. Then the Russian Republic launched a reintroduction programme. In 1977-1987 about 20,000 animals were translocated to more than 300 localities of 19 regions and autonomous republics of Russia (Figure 1). Most of the reintroduced populations did not increase in the first few years, and in many areas they declined. Nevertheless, the reintroduction programme should be considered successful: after an absence of 100 years the marmot is re-established in more than 10 regions of its former range.

The existing range of $M . \quad b$. bobac has expanded over the last three or four decades, at first due to natural migration from overpopulated colonies, and the penetration of new areas along small flat-bottomed valleys. Now there are 250,000 individuals, a 10-fold increase in numbers and it is clear that new ecological adaptations helped its survival; it has been able to thrive in abandoned villages and farmsteads, in pastures, in ravines and small flat-bottomed valleys where scrub had been reduced by overgrazing, and where meadow herbs had been replaced by ruderal species and plants of dry steppes. M. b. bobac also used agricultural lands when its numbers had increased, but has adapted most successfully to perennial grass crops.

The data obtained so far lead us to conclude that $M . b$. bobac has progressively adapted to living in areas under cereals, but particularly in areas under perennial herbs, and the extent of its adaptation is correlated with the duration of contact with the developed steppe. It is highest in the Ukraine, and lower in the Volga area.

The ecology of steppe marmot restoration has not been completely studied, but there have been useful studies on the grey marmot by S. B. Pole, A. A. Mikhailyuta and D. I. Bibikov (see Bibikov, 1988). Other family-colonial animals (for example, beavers) have very similar mechanisms of restoration. The process starts with the migration of single individuals from greatly reduced populations, pair formation, and then animal concentrations in new areas. In new colonies reproduction is fast: the portion of breeding females increases by $29-30$ per cent, the animals begin to reproduce at a younger age (about 25 per cent of 2-year-old females breed) and the litter size increases. In a growing population competition is low in the early years because there are many vacant dens and pastures. Family sites also occupy large territories. In these conditions the younger generation is growing rapidly and its death rate is low. After 5 years the density at the core of the colony reaches 100 or more individuals per sq $\mathrm{km}$. By that time the age structure changes, with a greater proportion of ageing individuals, the proportion of breeding females declines from 70 to 47 per cent, and the average size of a litter from 6.4 to 5 .

Overpopulation slows down reproduction and some individuals disperse, but they often face difficulties in finding a new site to settle. Natural dispersal from populations with reduced reproduction is wasteful; many ani- 


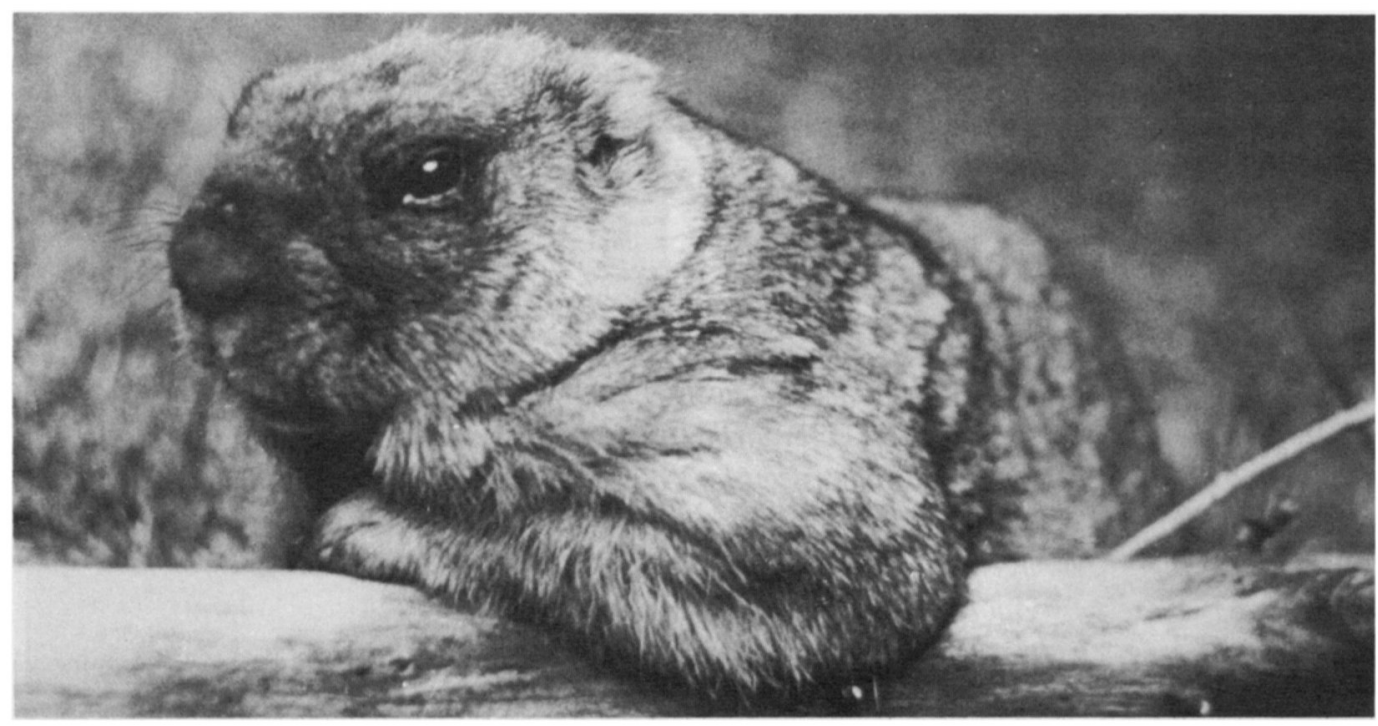

The steppe marmot (V. A. Jokazsky).

mals perish when migrating. Instead, populations should be controlled by means of strictly organized hunting and removal of individuals for reintroduction. The removal of offspring is ecologically justified and ensures optimum productivity.

\section{The future of the steppe marmot}

Considering the restoration history of $M . b$. bobac, its stabilization and increase in numbers, we think that previous fears that the marmot would gradually disappear in the range used for agriculture were groundless. Within its historical range there are still great areas of pastures, its optimum habitat, and these should persist for the foreseeable future.

Adaptations to man-made landscapes and to new foods, and a growing trust of man favour further increases in numbers. Reintroductions of $M . b$. bobac have already extended its range and if further dispersion is combined with scientifically-based hunting when necessary, and with conservation measures, we believe that by the beginning of the next century the numbers of the European subspecies will total $1,000,000$. A conservation programme is also under way for the Kazakhstan subspecies; its range has also expanded and numbers are expected to increase to $2,000,000$ by the beginning of the next century. That will allow us to raise the annual store of skins to 500,000 and of fat to 200 tons. As well as providing these useful products, increasing marmot populations could serve the interests of hunters, particularly those who wish to perpetuate traditional hunting methods.

\section{References}

Bibikov, D.I. 1988. Some ecological and behavioural characteristics of marmots in a population with low numbers, and in the process of its restoration. Actual Problems of Morphology and Ecology of Higher Vertebrates. Institute of Animal Morphology and Ecology, Moscow. Acad. Sci. USSR, part 2, 553-581.

Bibikov, D.I., and Dezhkin, A.V. 1988. European steppe marmot rehabilitation. Priroda, No 3, 46-49.

Popov, V.A. 1960. Mammals of the Volga-Kama Area. USSR Acad. of Sci. Kazan' Branch, Kazan', 210-222.

Zimina, R.P. and Gerasimov, I.P. 1971. Marmota periglacial expansion during the late Pleistocene (in Middle Europe). Bull. Moscow Naturalist Society, Biology Section. 76, 37-49.

Zimina, R.P. and Gerasimov, I.P. 1973. The periglacial expansion of marmots (Marmota) in Middle Europe during the late Pleistocene. J. Mammol. 54, 327-340.

D. Bibikov, Institute of Animal Morphology and Ecology, Leninsky pr 33, Moscow 117071, USSR. 